\title{
Epidemiological relationships among penicillin non- susceptible Streptococcus pneumoniae strains recovered in the Czech Republic
}

Correspondence

Helena Žemličková

hzemlickova@szu.cz

Received 1 August 2005

Accepted 4 January 2006

\author{
Helena Žemličková, Oto Melter and Pavla Urbášková \\ National Institute of Public Health, Šrobárova 48, 10042 Prague 10, Czech Republic
}

\begin{abstract}
Since 1986, penicillin non-susceptible pneumococci (PNSP) have been found in the Czech Republic. As documented by a nationwide study, the proportion of invasive strains with reduced susceptibility to penicillin has fluctuated around $5 \%$ in the past decade. Although the level of resistance to penicillin remains stable, the contribution of different capsular serotypes among the PNSP population varies. Whereas serotype $19 \mathrm{~A}$ was predominantly associated with penicillin resistance until 1997, serotype 9V became most common among PNSP strains in 1998. In a collection of PNSP strains $(n=225)$ isolated from 2000 to 2002 , the most frequent serotype was $9 \mathrm{~V}(n=91,40 \cdot 4 \%)$, followed by $19 \mathrm{~F}(n=30,13.3 \%)$ and $14(n=25,11.5 \%)$. PFGE and multilocus sequence typing were used to characterize a set of PNSP of the currently predominant serotypes $9 \mathrm{~V}(n=42), 14(n=15)$ and $19 \mathrm{~F}(n=14)$. The Spain ${ }^{9 \mathrm{~V}}$-3 clone [sequence type (ST) 156] was responsible for a large proportion ( $100 \%$ of serotype $9 \mathrm{~V}$ strains, $n=42 ; 93.3 \%$ of serotype 14 strains, $n=14$ ) of the analysed strains. A representative of the Taiwan ${ }^{19 F}-14$ clone (ST 236) was also recovered in the Czech Republic (a single isolate of serotype 19F). These findings confirm the spread of the major penicillin-resistant clones in the Czech Republic.
\end{abstract}

\section{INTRODUCTION}

The global occurrence of penicillin non-susceptible pneumococci (PNSP) has become a serious problem in the treatment of pneumococcal infections. A steady increase in penicillin resistance and the worldwide spread of penicillinresistant clones have been documented for the past two decades (Soares et al., 1993; Baquero, 1995; Coffey et al., 1995). In 2003, the mean proportion of PNSP isolates reported through the European Antimicrobial Resistance Surveillance System (EARSS) was $10 \%$; however, a wide variation between countries in the prevalence of PNSP, from $<1 \%$ in Estonia and Germany, to $36 \%$ in Romania, has been observed (European Antimicrobial Resistance Surveillance System, 2003). In the Czech Republic (formerly part of Czechoslovakia until 1992), the first PNSP strains were documented in 1986 (Janečková et al., 1989). Between 1996 and 2002, the prevalence rates of invasive Streptococcus pneumoniae strains with reduced susceptibility to penicillin oscillated around $5 \%$, as shown in a nationwide study performed by the National Reference Center for Antibiotics (European Antimicrobial Resistance Surveillance System, 2003; Urbášková et al., 2004). Out of 666 invasive pneumococci collected during this period, only one isolate was

Abbreviations: AOM, acute otitis media; MEF, middle-ear fluid; MLST, multilocus sequence typing; PMEN, Pneumococcal Molecular Epidemiology Network; PNSP, penicillin non-susceptible pneumococci; SLV, single-locus variant; ST, sequence type. penicillin resistant $\left(\mathrm{MIC} \geqslant 2 \mu \mathrm{g} \mathrm{ml}^{-1}\right)$, and 25 strains tested penicillin-intermediate (MIC $0 \cdot 125-1 \cdot 0 \mu \mathrm{g} \mathrm{ml}^{-1}$ ). From 1992, all consecutive isolates with reduced susceptibility to penicillin from child carriers and children with acute otitis media (AOM) were collected by 31 clinical microbiology laboratories distributed throughout the Czech Republic. From 1992 to 2002, 419 PNSP carriage strains and 236 PNSP strains isolated from middle-ear fluid (MEF) were referred to the National Institute of Public Health. In both of these sets, the proportion of strains highly resistant to penicillin was almost $20 \%$. Although the level of resistance to penicillin has remained stable in the past decade, changes in the contribution of different capsular serotypes in the PNSP population have been noted. Since its first isolation in 1994, serotype $9 \mathrm{~V}$ has gradually replaced serotype 19A, which was highly prevalent in the Czech Republic until 1997 (Urbáśková \& Motlová, 1999; Urbášková et al., 2004). Among non-invasive PNSP strains, the proportion of serotype $9 \mathrm{~V}$ increased from $0 \%$ in 1992 to $46.5 \%$ in 2002 , while that of serotype 19A decreased from $58 \cdot 5 \%$ to $16 \cdot 3 \%$ during the same period. Since 1998, serotype $9 \mathrm{~V}$ has become predominant among the PNSP serotypes, followed by $19 \mathrm{~F}$ and 14 (Urbášková et al., 2004).

Only fragmentary data are available about the genetic background of PNSP strains isolated in the Czech Republic to date. PFGE analysis (Sa Figueiredo et al., 1995) of 72 PNSP strains collected from clinical specimens in the Czech and Slovak Republics between 1990 and 1992 showed high clonal 
uniformity of highly penicillin-resistant strains of serotypes 14 and 19A. Isolates of serotype 14 belonged to a major clonal group later included in the Pneumococcal Molecular Epidemiology Network (PMEN) as the $\mathrm{CSR}^{14}-10$ clone (McGee et al., 2001). Isolates of serotype 19A were divided into two subgroups, one of which was indistinguishable from the multiresistant Hungary ${ }^{19 \mathrm{~A}}-6$ clone, and the other of which was unique: its representative isolates were later accepted in the PMEN as the $\mathrm{CSR}^{19 \mathrm{~A}}-11$ clone (McGee et al., 2001). Low-resistance isolates of serotypes $6 \mathrm{~A} / \mathrm{B}, 14,15 \mathrm{~B}$, $19 \mathrm{~F}, 19 \mathrm{~A}$ and $23 \mathrm{~F}$ showed a high degree of variation in the chromosomal background, with 20 different PFGE patterns found for 32 isolates. In the late 1990s, clinical isolates of serotypes $9 \mathrm{~V}(n=10), 19 \mathrm{~F}(n=1)$ and $23 \mathrm{~F}(n=7)$ referred to Brian Spratt, St Mary's Hospital, London, UK, were identified by multilocus sequence typing (MLST) as members of the Spain ${ }^{9 \mathrm{~V}}-3$ and Spain ${ }^{23 \mathrm{~F}}-1$ clones. Also, clonal relatedness of 19A strains $(n=4)$ with the Hungary ${ }^{19 A}-6$ clone was proved: they were found to be a single-locus variant (SLV) of this clone (www.mlst.net).

The present study combined the PFGE and MLST methods to characterize PNSP strains of the currently predominant serotypes 9V, 19F and 14 collected in the Czech Republic from 2000 to 2002 .

\section{METHODS}

Isolates. A collection of 71 PNSP of serotypes $9 \mathrm{~V}(n=42), 19 \mathrm{~F}$ $(n=14)$ and $14(n=15)$, referred to the National Institute of Public Health by 31 microbiology labs in 21 cities between 2000 and 2002, was studied (Table 1). The study isolates were randomly selected to be as heterogeneous as possible in terms of susceptibility to antibiotics and geographical origin. Regarding the site of isolation, three sets of PNSP strains from three national surveillance projects were used: 37 carriage strains from nasopharyngeal swabs of healthy children, 22 isolates from MEF of children aged 5 years and younger, and 12 invasive isolates from blood $(n=10)$ and cerebrospinal fluid $(n=2)$ of patients regardless of age.

Antibiotic susceptibility testing. MICs of penicillin, erythromysulfamethoxazole were determined by the broth microdilution method, as described by the Clinical and Laboratory Standards Institute (CLSI), formerly the National Committee for Clinical Laboratory Standards. To read the results, the CLSI interpretation criteria were used, except for tetracycline, erythromycin and clindamycin, for which the CLSI intermediate values were considered to constitute resistance (National Committee for Clinical Laboratory Standards, 2000).

Serotyping. The strains were serotyped by Quellung reaction, using Denmark (Sorensen, 1993).

PFGE. PFGE of chromosomal DNA was performed as previously described (Soares et al., 1993). Reference strains of epidemic clones Spain $^{9 \mathrm{~V}}-3$ (ATCC 700671), CSR ${ }^{14}-10$ (ATCC 700677) and Taiwan $^{19 F}$-14 (ATCC 700905), kindly provided by Hermínia de Lencastre, were used for comparison. Isolates with identical profiles belonged to the same type. Isolates that differed by one to six bands were assigned to different subtypes, and were considered to be members of the same clonal group. cin, clindamycin, chloramphenicol, tetracycline and trimethoprimtype and factor sera provided by the Statens Institut, Copenhagen,

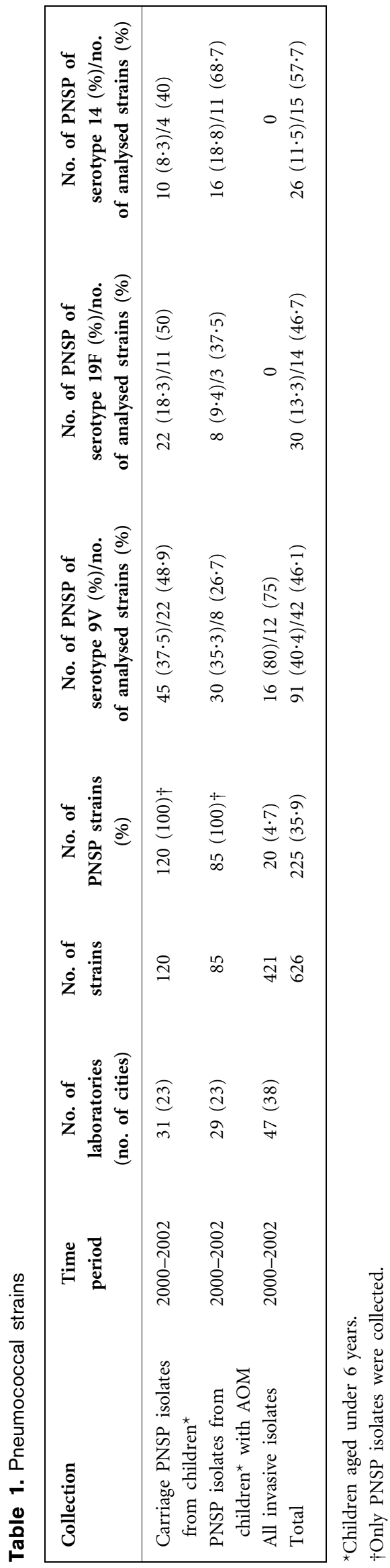


MLST. The sequences of the $\sim 450$ bp internal fragments from the aroE, $g d h, g k i, r e c P$, spi, xpt and $d d l$ genes were amplified by PCR using primers, as described by Enright \& Spratt (1998). Alleles and sequence type (STs) were assigned using the data on $S$. pneumoniae available at the MLST web site (www.mlst.net). Allelic profiles of new STs were electronically submitted to the S. pneumoniae MLST database. Isolates with identical allelic profiles or differing in a single locus were considered as closely related; isolates differing in two loci were assumed to be possibly genetically related.

\section{RESULTS AND DISCUSSION}

\section{PFGE analysis}

Out of the 71 isolates analysed by PFGE, 69 had either identical or related PFGE patterns generated by SmaI digestion (Table 2). Comparison of the electrophoretic patterns revealed eight related PFGE subtypes of this dominant clone, assigned as clone A. PFGE subtypes A1, A5 and A8 were shared by the pairs of serotypes $9 \mathrm{~V}$ and 19F, 14 and 19F, and $9 \mathrm{~V}$ and 14, respectively. Subtype A2 was common to isolates of all study serotypes. Most strains $(n=64,92 \cdot 7 \%)$ of clone A were intermediately penicillin-resistant (MIC $0 \cdot 125-$ $1 \cdot 0 \mu \mathrm{g} \mathrm{ml}^{-1}$ ), and five strains only were highly resistant to penicillin $\left(\mathrm{MIC} \geqslant 2 \mu \mathrm{g} \mathrm{ml}^{-1}\right.$ ). All strains of clone A were resistant to trimethoprim-sulfamethoxazole (MIC $\geqslant 4 / 76 \mu \mathrm{g}$ $\left.\mathrm{ml}^{-1}\right)$; some strains $(n=18,25 \cdot 3 \%)$ were also resistant to erythromycin (MIC $\left.\geqslant 0.5 \mu \mathrm{g} \mathrm{ml}^{-1}\right)$, clindamycin $(n=14$, $19 \cdot 7 \%, \quad$ MIC $\left.\geqslant 1 \mu \mathrm{g} \mathrm{ml}^{-1}\right)$, chloramphenicol $(n=13$, $\left.18 \cdot 8 \%, \mathrm{MIC} \geqslant 8 \mu \mathrm{g} \mathrm{ml}^{-1}\right)$ or tetracycline $(n=6,8 \cdot 7 \%$, $\mathrm{MIC} \geqslant 4 \mu \mathrm{g} \mathrm{ml}^{-1}$ ). Resistance to these antibiotics was predominantly associated with serotype 14 strains belonging to subtype A5, all isolates of this serotype $(n=12)$ being resistant to erythromycin, clindamycin and chloramphenicol, and five to tetracycline also. In contrast, isolates of serotype 19F belonging to subtype A5 were erythromycin, clindamycin, chloramphenicol and tetracycline susceptible. The PFGE patterns of clone A subtypes were compared with that generated by a Spain ${ }^{9 \mathrm{~V}}-3$ isolate. The profiles were identical (subtype A1) or very similar to that of the international Spain $^{9 \mathrm{~V}}-3$ clone (maximum difference of six bands), which indicates that the isolates are genotypically identical or related, and can be considered to be members of the same clone. Only two strains of serotype 19F were not related to clone A; moreover, they differed from each other by seven bands in PFGE patterns and were assigned to types $\mathrm{C} 1$ and D1. Susceptibility profiles of strains are shown in Table 3. The comparison of PFGE patterns with that generated by a representative isolate of the Taiwan ${ }^{19 \mathrm{~F}}$ - 14 international clone showed high similarity (four-band difference) of the isolate to type D1, and therefore the relatedness of type D1 to the Taiwan ${ }^{19 F}-14$ clone; the PFGE pattern of a $\mathrm{C} 1$ type isolate differed by seven bands from that of the Taiwan ${ }^{19 \mathrm{~F}}-14$ clone, and consequently the isolate was considered to be unrelated to this clone.

\section{MLST analysis}

Two representative isolates, if available, of each PFGE subtype of each serotype were chosen for MLST analysis (Table 2). A total of 24 strains were characterized by MLST. The results of MLST were assumed to be shared by other isolates of the same serotype within a PFGE subtype. Data on serotype, demographic characteristics, antibiotic susceptibility profile and results of PFGE and MLST for individual isolates are given in Table 3.

Within clone A, three different STs were found: ST 156 $(n=15)$, ST $380(n=6)$ and ST $143(n=1)$. Allelic profiles identical to that of the international Spain ${ }^{9 \mathrm{~V}}-3$ clone (ST $156)$ were found in all of the analysed isolates of serotype $9 \mathrm{~V}$ $(n=11)$, and in four out of five isolates of serotype 14 , indicating that they were serotype variants of this clone. Both ST 143 and ST 380 are double-locus variants of ST 156; therefore, strains possessing either ST 143 or ST 380 were considered to be possibly related to ST 156. The ST 143 allelic profile was found in a single isolate of serotype 14, which was the only strain of PFGE pattern A6. Isolates of

Table 2. MLST results and PFGE patterns of isolates of selected serotypes

\begin{tabular}{|c|c|c|c|c|}
\hline \multirow[t]{2}{*}{$\begin{array}{l}\text { PFGE } \\
\text { pattern }\end{array}$} & \multicolumn{3}{|c|}{$\begin{array}{l}\text { No. of isolates of each serotype } \\
\text { (ST of representative isolates) }\end{array}$} & \multirow[t]{2}{*}{$\begin{array}{l}\text { Total (no. of strains } \\
\text { analysed by MLST) }\end{array}$} \\
\hline & $9 \mathrm{~V}$ & 14 & $19 \mathrm{~F}$ & \\
\hline A1 & 26 (ST 156) & & 2 (ST 380) & $28(4)$ \\
\hline $\mathrm{A} 2$ & 7 (ST 156) & 1 (ST 156) & 7 (ST 380) & $15(5)$ \\
\hline A3 & 1 (ST 156) & & & $1(1)$ \\
\hline A4 & 4 (ST 156) & & & $4(2)$ \\
\hline A5 & & 12 (ST 156) & $3(\mathrm{ST} 380)$ & $15(4)$ \\
\hline A6 & & 1 (ST 143) & & $1(1)$ \\
\hline A7 & 2 (ST 156) & & & $2(2)$ \\
\hline A8 & 2 (ST 156) & 1 (ST 156) & & $3(3)$ \\
\hline $\mathrm{C} 1$ & & & 1 (ST 1657) & $1(1)$ \\
\hline D1 & & & 1 (ST 236) & $1(1)$ \\
\hline Total & 42 & 15 & 14 & $71(24)$ \\
\hline
\end{tabular}


Table 3. Characteristics of 24 invasive PNSP strains isolated in the Czech Republic

\begin{tabular}{|c|c|c|c|c|c|c|c|c|c|c|c|c|c|c|c|c|c|c|c|c|c|c|}
\hline \multirow[t]{2}{*}{ Serotype } & \multirow{2}{*}{$\begin{array}{c}\text { Strain } \\
\text { no. }\end{array}$} & \multirow{2}{*}{$\begin{array}{l}\text { Year of } \\
\text { isolation }\end{array}$} & \multirow[t]{2}{*}{ City } & \multirow[t]{2}{*}{$\operatorname{Sex}^{\star}$} & \multirow[t]{2}{*}{ Age $\dagger$} & \multirow[t]{2}{*}{ Source $\ddagger$} & \multicolumn{7}{|c|}{$\operatorname{MIC}\left(\mathrm{mg} \mathrm{l}^{-1}\right)$ of: $§$} & \multirow{2}{*}{$\begin{array}{l}\text { PFGE } \\
\text { type }\end{array}$} & \multirow[t]{2}{*}{ ST } & \multicolumn{7}{|c|}{ Allelic profile } \\
\hline & & & & & & & PEN & CTX & CMP & TET & ERY & CLI & SXT & & & $\operatorname{aroE}$ & $g d h$ & $g k i$ & rec & spi & $x p t$ & $d d l$ \\
\hline \multirow[t]{11}{*}{$9 \mathrm{~V}$} & 4405 & 2001 & Č. Budějovice & M & $68 \mathrm{y}$ & Blood & $0 \cdot 5$ & $0 \cdot 5$ & 2 & $0 \cdot 25$ & $0 \cdot 063$ & $0 \cdot 125$ & $>32$ & Al & 156 & 7 & 11 & 10 & 1 & 6 & 8 & 1 \\
\hline & 7085 & 2001 & Praha & $\mathrm{F}$ & $10 \mathrm{~m}$ & MEF & 4 & 1 & 4 & $0 \cdot 25$ & $0 \cdot 125$ & $0 \cdot 125$ & $>32$ & Al & 156 & 7 & 11 & 10 & 1 & 6 & 8 & 1 \\
\hline & 3677 & 2001 & Pardubice & $\mathrm{M}$ & $52 \mathrm{y}$ & Blood & $0 \cdot 125$ & $0 \cdot 125$ & 4 & $0 \cdot 25$ & $0 \cdot 25$ & $0 \cdot 125$ & $>32$ & A2 & 156 & 7 & 11 & 10 & 1 & 6 & 8 & 1 \\
\hline & 7197 & 2001 & Brno & $\mathrm{M}$ & $1 \mathrm{y}$ & NP & $0 \cdot 5$ & $0 \cdot 5$ & 4 & $0 \cdot 25$ & $0 \cdot 125$ & $0 \cdot 125$ & $>32$ & A2 & 156 & 7 & 11 & 10 & 1 & 6 & 8 & 1 \\
\hline & 1278 & 2000 & Most & $\mathrm{M}$ & $1 \mathrm{y}$ & NP & 1 & $0 \cdot 5$ & 4 & $0 \cdot 25$ & $0 \cdot 032$ & $0 \cdot 063$ & $>32$ & A3 & 156 & 7 & 11 & 10 & 1 & 6 & 8 & 1 \\
\hline & 3831 & 2002 & Plzeň & $\mathrm{M}$ & $32 \mathrm{y}$ & Blood & 1 & 1 & $0 \cdot 5$ & $0 \cdot 5$ & $0 \cdot 125$ & $0 \cdot 25$ & $>32$ & A4 & 156 & 7 & 11 & 10 & 1 & 6 & 8 & 1 \\
\hline & 205 & 2000 & Praha & $\mathrm{M}$ & $79 \mathrm{y}$ & Blood & $0 \cdot 125$ & $0 \cdot 063$ & 1 & $0 \cdot 25$ & $0 \cdot 063$ & $0 \cdot 063$ & 32 & A4 & 156 & 7 & 11 & 10 & 1 & 6 & 8 & 1 \\
\hline & 2427 & 2000 & Ostrava & $\mathrm{F}$ & $11 \mathrm{~m}$ & CSF & 1 & 1 & 4 & $0 \cdot 5$ & $>32$ & $0 \cdot 125$ & $>32$ & A7 & 156 & 7 & 11 & 10 & 1 & 6 & 8 & 1 \\
\hline & 3885 & 2002 & Ostrava & $\mathrm{F}$ & $2 \mathrm{~m}$ & NP & 1 & 1 & 4 & $0 \cdot 25$ & $>32$ & $0 \cdot 25$ & $>32$ & A7 & 156 & 7 & 11 & 10 & 1 & 6 & 8 & 1 \\
\hline & 7447 & 2001 & Praha & $\mathrm{M}$ & $1 \mathrm{y}$ & MEF & 4 & 1 & 2 & $0 \cdot 25$ & $0 \cdot 063$ & $0 \cdot 125$ & $>32$ & A8 & 156 & 7 & 11 & 10 & 1 & 6 & 8 & 1 \\
\hline & 3884 & 2002 & Ostrava & F & $53 \mathrm{y}$ & CSF & 1 & 1 & 4 & $0 \cdot 5$ & $0 \cdot 125$ & $0 \cdot 125$ & $>32$ & A8 & 156 & 7 & 11 & 10 & 1 & 6 & 8 & 1 \\
\hline \multirow[t]{5}{*}{14} & 5734 & 2001 & Náchod & $\mathrm{M}$ & $1 \mathrm{y}$ & NP & 1 & 1 & 2 & $0 \cdot 25$ & $0 \cdot 125$ & $0 \cdot 063$ & $>32$ & A2 & 156 & 7 & 11 & 10 & 1 & 6 & 8 & 1 \\
\hline & 1241 & 2000 & Nový Jičín & $\mathrm{F}$ & $1 \mathrm{y}$ & MEF & 1 & 1 & 16 & $0 \cdot 5$ & $>32$ & $>32$ & $>32$ & A5 & 156 & 7 & 11 & 10 & 1 & 6 & 8 & 1 \\
\hline & 6966 & 2001 & Př́bram & $\mathrm{M}$ & $4 \mathrm{y}$ & MEF & 2 & 1 & 32 & $0 \cdot 25$ & 16 & $>32$ & $>32$ & A5 & 156 & 7 & 11 & 10 & 1 & 6 & 8 & 1 \\
\hline & 2207 & 2000 & Plzeň & $\mathrm{M}$ & $1 \mathrm{~m}$ & MEF & 1 & $0 \cdot 25$ & 4 & $>32$ & $>32$ & $>32$ & $>32$ & A6 & 143 & 7 & 5 & 10 & 18 & 6 & 8 & 1 \\
\hline & 293 & 2000 & Plzeň & $\mathrm{M}$ & $5 \mathrm{y}$ & NP & $0 \cdot 25$ & $0 \cdot 125$ & 16 & $0 \cdot 5$ & $>32$ & $>32$ & $>32$ & A8 & 156 & 7 & 11 & 10 & 1 & 6 & 8 & 1 \\
\hline \multirow[t]{8}{*}{$19 \mathrm{~F}$} & 1267 & 2000 & Kladno & $\mathrm{F}$ & $11 \mathrm{~m}$ & MEF & $0 \cdot 125$ & $0 \cdot 125$ & 4 & $0 \cdot 25$ & $0 \cdot 063$ & $0 \cdot 063$ & $>32$ & Al & 380 & 7 & 11 & 19 & 1 & 6 & 20 & 1 \\
\hline & 889 & 2000 & Praha & M & $1 \mathrm{y}$ & NP & $0 \cdot 25$ & 1 & 2 & $0 \cdot 5$ & $0 \cdot 032$ & $0 \cdot 125$ & 32 & $\mathrm{~A} 1$ & 380 & 7 & 11 & 19 & 1 & 6 & 20 & 1 \\
\hline & 6088 & 2001 & Praha & $\mathrm{M}$ & $1 \mathrm{y}$ & NP & $0 \cdot 125$ & $0 \cdot 25$ & 2 & $0 \cdot 125$ & $0 \cdot 125$ & 0.063 & $>32$ & A2 & 380 & 7 & 11 & 19 & 1 & 6 & 20 & 1 \\
\hline & 172 & 2000 & Ostrava & $\mathrm{F}$ & $1 \mathrm{y}$ & NP & $0 \cdot 125$ & $0 \cdot 25$ & 2 & $0 \cdot 25$ & $0 \cdot 063$ & $0 \cdot 125$ & $>32$ & $\mathrm{~A} 2$ & 380 & 7 & 11 & 19 & 1 & 6 & 20 & 1 \\
\hline & 1947 & 2000 & Praha & M & $1 \mathrm{y}$ & NP & $0 \cdot 125$ & $0 \cdot 125$ & 4 & $0 \cdot 25$ & $0 \cdot 063$ & 0.063 & 32 & A5 & 380 & 7 & 11 & 19 & 1 & 6 & 20 & 1 \\
\hline & 198 & 2000 & Brno & $\mathrm{F}$ & $2 y$ & MEF & $0 \cdot 25$ & $0 \cdot 25$ & 4 & $0 \cdot 25$ & $0 \cdot 063$ & $0 \cdot 063$ & $>32$ & A5 & 380 & 7 & 11 & 19 & 1 & 6 & 20 & 1 \\
\hline & 4257 & 2001 & Praha & $\mathrm{M}$ & $3 y$ & NP & $0 \cdot 125$ & $0 \cdot 125$ & 2 & 2 & 2 & $0 \cdot 125$ & $>32$ & $\mathrm{C} 1$ & $1657 \mid I$ & 15 & 16 & 19 & 15 & 6 & 20 & 97 \\
\hline & 4401 & 2001 & Praha & $\mathrm{M}$ & $5 \mathrm{y}$ & MEF & $0 \cdot 5$ & $0 \cdot 25$ & 4 & 32 & 8 & $0 \cdot 125$ & 32 & D1 & 236 & 15 & 16 & 19 & 15 & 6 & 20 & 26 \\
\hline
\end{tabular}

${ }^{\star} \mathrm{F}$, female; $\mathrm{M}$, male.

†y, Year; m, month.

‡CSF, cerebrospinal fluid; NP, nasopharynx.

§EN, penicillin; CTX, cefotaxime; CMP, chloramphenicol; TET, tetracycline; ERY, erythromycin; CLI, clindamycin; SXT, trimethoprim-sulfamethoxazole. IINew ST. 
penicillin-resistant serotype 14 belonging to ST 143 have been found in Poland (year of isolation: 1994) and Hungary (year of isolation: 2002) (www.mlst.net). ST 380, the other identified double-locus variant ST of the Spain ${ }^{9 \mathrm{~V}}-3$ clone, was only identified in serotype $19 \mathrm{~F}$ isolates. According to the MLST database, a single isolate of ST 380 has been included in the S. pneumoniae dataset: a Czech strain isolated in 1997. The remaining two strains of serotype 19F were of ST 236 and ST 1657. ST 236 was assigned to the Taiwan ${ }^{19 \mathrm{~F}}$ - 14 clone. A novel ST 1657 was found to be an SLV of ST 236.

As documented by other authors (Sá-Leão et al., 2001; Gertz et al., 2003; Serrano et al., 2005), the results obtained by PFGE and MLST may not always overlap. A possible explanation is the difference in discriminatory power between these molecular techniques. In our study, discrepancies were also noted. For example, serotype 19F isolates had PFGE subtype A profiles indistinguishable from those generated by isolates of serotypes $9 \mathrm{~V}$ and 14 , while their allelic profiles differed in two of the seven loci when characterized by MLST. Notwithstanding these variations, all of the isolates belonging to clone A appeared to be genetically related by MLST also, when a less stringent approach (five of seven shared alleles) to define a clonal group (Feil et al., 2004) was applied. On the other hand, strains 4257 and 4401 of serotype 19F had different PFGE types, but shared six of seven loci when characterized by MLST. This could be explained by the classification of isolates into PFGE types being based on a seven-band difference in profiles.

The international spread of a restricted number of multiresistant clones has been documented and the propensity to horizontal gene recombination in these clones has been verified (Coffey et al., 1991, 1999; Munoz et al., 1991; Gasc et al., 1995). The present study demonstrated the Spain ${ }^{9 \mathrm{~V}}-3$ clone (ST 156) to make a major contribution to the PNSP population in the Czech Republic. Apparently, the genetic background of this clone is not restricted to serotype $9 \mathrm{~V}$, but is also disseminated within serotype 14 and 19F. In contrast, none of the current isolates of serotype 14 was related to the clone $\mathrm{CSR}^{14}-10$ described previously in the former Czechoslovakia.

The genetic background of the Spain ${ }^{9 \mathrm{~V}}-3$ clone in serotypes 11A 14, and 19F has been reported previously (Coffey et al., 1999; Enright et al., 1999; Porat et al., 2004). The ability of pneumococci to undergo capsular transformation could compromise the efficacy of the conjugate pneumococcal vaccine, as the number of serotypes contained in the vaccine is limited (Obaro \& Adegbola, 2002; McEllistrem et al., 2003). The available 7 -valent vaccine includes conjugates derived from polysaccharides of types $4,6 \mathrm{~B}, 9 \mathrm{~V}, 14,18 \mathrm{C}, 19 \mathrm{~F}$ and 23F. Porat et al. (2004) have documented non-vaccine serotype $11 \mathrm{~A}$ variants of the international $\mathrm{Spain}^{9 \mathrm{~V}}-3$ clone, one of the major antibiotic-non-susceptible clones, among carriage and MEF isolates obtained from Israeli children. The authors imply that although the increased prevalence of serotype 11A may be of minor consequence, since this serotype has a relatively low potential to cause invasive disease, the conjugate vaccine would open a reservoir for this serotype as a cause of AOM. In our study, isolates of serotype 11A were not included for analysis, as only a single penicillin-intermediate strain of this serotype was referred to the National Institute of Public Health between 2000 and 2002. Nevertheless, continued surveillance of pneumococcal serotype distribution will be of concern when the pneumococcal vaccine is widely used in the Czech Republic.

Representatives of the Taiwan ${ }^{19 F}$-14 clone (ST 236) and SLVs of this ST were also detected in the Czech Republic. Multidrug-resistant strains of ST 236 have been found in Taiwan since at least 1993 (Shi et al., 1998). The Taiwan ${ }^{19 \mathrm{~F}}$ 14 clone is highly predominant among penicillin-resistant strains in far-eastern countries (Song et al., 1997; Shi et al., 1998); however, it appears already to have spread intercontinentally, as two penicillin-resistant isolates of serotype $19 \mathrm{~F}$ with allelic profiles similar to that of Taiwan ${ }^{19 \mathrm{~F}}-14$ have been identified in the UK (Enright \& Spratt, 1998). Richter et al. (2002) have provided evidence of the global spread of this clone, as penicillin-resistant isolates of serotype $19 \mathrm{~F}$ collected in the USA are grouped into the same cluster with this clone.

Despite stable low rates of resistance to penicillin in the Czech Republic, a significant shift in serotype distribution has been reported (Urbášková \& Motlová, 1999; Urbášková et al., 2004). The shift could be explained by the introduction of the Spain ${ }^{9 \mathrm{~V}}-3$ clone into the country from highprevalence western European regions after the political changes in 1989, with the subsequent sharp rise in international travel. Interestingly, in results parallel to those from the Czech Republic, Buxbaum et al. (2004) found serogroup 9 to have become predominant among the penicillin nonsusceptible serogroups in Austria in 1998. In contrast to the Czech Republic, this change was accompanied by a dramatic rise in penicillin resistance, which almost doubled the rate in Austria to nearly $10 \%$. Due to geographic proximity, resistant strains of serogroup 9 may have been imported into the Czech Republic from Austria; nevertheless, this hypothesis still remains to be confirmed, as detailed information on the genetic background of Austrian strains is not yet available. Moreover, other unknown factors might have been involved in the expansion of the Spain ${ }^{9 \mathrm{~V}}-3$ clone, given that it is not clear why other pandemic multiresistant clones did not spread in the country with the same impact.

\section{ACKNOWLEDGEMENTS}

We thank Hermínia de Lencastre for providing the PMEN reference strains, Jitka Motlová for serotyping, Martin Musílek for carrying out MLST, and the regional microbiology laboratories for providing pneumococcal isolates. This study was partly supported by contract LSHM-CT-2003-503413 (Pneumococcal Resistance Epidemicity and Virulence - an International Study) (PREVIS), from the European Commission. We acknowledge the use of the pneumococcal MLST database, which is located at Imperial College, London, UK, and is funded by the Wellcome Trust. 


\section{REFERENCES}

Baquero, F. (1995). Pneumococcal resistance to $\beta$-lactam antibiotics: a global geographic overview. Microb Drug Resist 1, 115-120.

Buxbaum, A., Forsthuber, S., Graninger, W. \& Georgopoulos, A. (2004). Serotype distribution and antimicrobial resistance of Streptococcus pneumoniae in Austria. J Antimicrob Chemother 54, 247-250.

Coffey, T. J., Dowson, C. G., Daniels, M., Zhou, J., Martin, C., Spratt, B. G. \& Musser, J. M. (1991). Horizontal transfer of multiple penicillin-binding protein genes, and capsular biosynthetic genes, in natural populations of Streptococcus pneumoniae. Mol Microbiol 5, $2255-2260$

Coffey, T. J., Dowson, C. G., Daniels, M. \& Spratt, B. G. (1995). Genetics and molecular biology of $\beta$-lactam-resistant pneumococci. Microb Drug Resist 1, 25-30.

Coffey, T. J., Daniels, M., Enright, M. C. \& Spratt, B. G. (1999). Serotype 14 variants of the Spanish penicillin-resistant serotype $9 \mathrm{~V}$ clone of Streptococcus pneumoniae arose by large recombinational replacements of the cpsA-pbpla region. Microbiology 145, 2023-2031.

European Antimicrobial Resistance Surveillance System (2004). European Antimicrobial Resistance Surveillance System annual report 2003. Ongoing surveillance of S. pneumoniae, S. aureus, E. coli, E. faecium, E. faecalis. Bilthoven, The Netherlands: RIVM.

Enright, M. C. \& Spratt, B. G. (1998). A multilocus sequence typing scheme for Streptococcus pneumoniae: identification of clones associated with serious invasive disease. Microbiology 144, 3049-3060.

Enright, M. C., Fenoll, A., Griffiths, D. \& Spratt, B. G. (1999). The three major Spanish clones of penicillin-resistant Streptococcus pneumoniae are the most common clones recovered in recent cases of meningitis in Spain. J Clin Microb 37, 3210-3216.

Feil, E. J., Li, B. C., Aanensen, D. M., Hanage, W. P. \& Spratt, B. G. (2004). eBURST: inferring patterns of evolutionary descent among clusters of related bacterial genotypes from multilocus sequence typing data. J Bacteriol 186, 1518-1530.

Gasc, A.-M., Geslin, P. \& Sicard, A. M. (1995). Relatedness of penicillin-resistant Streptococcus pneumoniae serogroup 9 strains from France and Spain. Microbiology 141, 623-627.

Gertz, R. E., Jr, McEllistrem, C. M., Boxrud, D. J. \& 9 other authors (2003). Clonal distribution of invasive pneumococcal isolates from children and selected adults in the United States prior to 7-valent conjugate vaccine introduction. J Clin Microbiol 41, 4194-4216.

Janečková, V., Toršová, V. \& Chmelařová, E. (1989). The incidence of Streptococcus pneumoniae strains with resistance to penicillin. Cesk Epidemiol Mikrobiol Imunol 38, 342-347.

McEllistrem, M. C., Adams, J., Mason, E. O. \& Wald, E. R. (2003). Epidemiology of acute otitis media caused by Streptococcus pneumoniae before and after licensure of the 7-valent pneumococcal protein conjugate vaccine. J Infect Dis 188, 1679-1684.

McGee, L., McDougal, L., Zhou, J. \& 8 other authors (2001). Nomenclature of major antimicrobial-resistant clones of Streptococcus pneumoniae defined by the pneumococcal molecular epidemiology network. J Clin Microbiol 39, 2565-2571.

Munoz, R., Coffey, T. J., Daniels, M. \& 8 other authors (1991). Intercontinental spread of a multiresistant clone of serotype $23 \mathrm{~F}$ Streptococcus pneumoniae. J Infect Dis 164, 302-306.

Obaro, S. \& Adegbola, R. (2002). The pneumococcus: carriage, disease and conjugate vaccines. J Med Microbiol 51, 98-104.

National Committee for Clinical Laboratory Standards (2000). Methods for Dilution Antimicrobial Susceptibility Tests for Bacteria that Grow Aerobically (M7-A4), Approved standard (M100-S10), 5th edn. Wayne, PA: National Committee for Clinical Laboratory Standards.

Porat, N., Arguedas, A., Spratt, B. G., Trefler, R., Brilla, E., Loaiza, C., Godoy, D., Bilek, N. \& Dagan, R. (2004). Emergence of penicillinnonsusceptible Streptococcus pneumoniae clones expressing serotypes not present in the antipneumococcal conjugate vaccine. J Infect Dis 190, 2154-2161.

Richter, S. S., Heilmann, K. P., Coffman, S. L., Huyng, H. K., Brueggemann, A. B., Pfaller, M. A. \& Doern, G. V. (2002). The molecular epidemiology of penicillin-resistant Streptococcus pneumoniae in the United States, 1994-2000. Clin Infect Dis 34, 330-339.

Sa Figueiredo, A. M., Austrian, R., Urbaskova, P., Texeira, L. A. \& Tomasz, A. (1995). Novel penicillin-resistant clones of Streptococcus pneumoniae in the Czech Republic and in Slovakia. Microb Drug Resistance 1, 71-78.

Sá-Leão, R., Tomasz, A. \& de Lencastre, H. (2001). Multilocus sequence typing of Streptococcus pneumoniae clones with unusual drug resistance patterns: genetic backgrounds and relatedness to other epidemic clones. J Infect Dis 184, 1206-1210.

Serrano, I., Melo-Cristino, J., Carriço, J. A. \& Ramirez, M. (2005). Characterization of the genetic lineages responsible for pneumococcal invasive disease in Portugal. J Clin Microbiol 43, 1706-1715.

Shi, Z. Y., Enright, M. C., Wilkinson, P., Griffiths, D. \& Spratt, B. G. (1998). Identification of three major clones of multiply antibioticresistant Streptococcus pneumoniae in Taiwanese hospitals by multilocus sequence typing. J Clin Microbiol 36, 3514-3519.

Soares, S., Kristinsson, K. G., Muser, J. M. \& Tomasz, A. (1993). Evidence for the introduction of a multiresistant clone of serotype 6B Streptococcus pneumoniae from Spain to Iceland in the late 1980s. $J$ Infect Dis 168, 158-163.

Song, J. H., Yang, J. W., Peck, K. R., Kim, S., Lee, N. Y., Jacobs, M. R., Applebaum, P. C. \& Pai, C. H. (1997). Spread of multidrug-resistant Streptococcus pneumoniae in South Korea. Clin Infect Dis 25, 747-749.

Sorensen, U. B. (1993). Typing of pneumococci by using 12 pooled antisera. J Clin Microbiol 31, 2097-2100.

Urbášková, P. \& Motlová, J. (1999). Occurrence of Streptococcus pneumoniae resistant to penicillin and other antibiotics in the Czech Republic from 1996 to 1998. Klin Mikrobiol Inf Lek 5, 65-71.

Urbášková, P., Motlová, J. \& Žemličková, H. (2004). Antibiotic resistance in invasive pneumococci and their serotypes in the Czech Republic. Cas Lek Cesk 143, 178-183. 